\title{
Excited-State Double-Proton Transfer on 3-Methyl-7-azaindole in a Single Crystal: Deuterium Isotope/Tunneling Effect
}

\author{
Wei-Shan Yu, ${ }^{\dagger}$ Chung-Chih Cheng, ${ }^{\ddagger}$ Chen-Pin Chang, ${ }^{\ddagger}$ Guo-Ray Wu, ${ }^{\dagger}$ Chin-Hao Hsu, ${ }^{\dagger}$ and \\ Pi-Tai Chou $*,+\S$ \\ Department of Chemistry, National Chung-Cheng University, Chia-Yi, Taiwan, Republic of China, Department \\ of Chemistry, Fu Jen Catholic University, Shin Chuang, Taiwan, Republic of China, and Department of \\ Chemistry, National Taiwan University, Taipei, Taiwan, Republic of China
}

Received: February 12, 2002; In Final Form: June 8, 2002

\begin{abstract}
Unlike 7-azaindole consisting of the tetrameric configuration, 3-methyl-7-azaindole (3MAI) exists solely as intact double hydrogen-bonded dimeric forms in a single crystal. Both steady-state and time-resolved measurements down to $8.0 \mathrm{~K}$ reveal remarkable deuterium isotope effects on the rate of excited-state double proton transfer (ESDPT) in the N(1)-deuterated 3MAI (3MAI- $d$ ) single crystal. The rates of ESDPT for the $3 \mathrm{MAI}-d$ dimer resolved at $<150 \mathrm{~K}$ are mainly governed by the proton tunneling mechanism. At $<12 \mathrm{~K}$, the nearly temperature-independent ESDPT dynamics lead us to qualitatively deduce a barrier height of $\sim 1.73$ $\mathrm{kcal} / \mathrm{mol}$ for the 3MAI- $d$ dimer. The results provide an ideal model to investigate the intrinsic ESDPT dynamics for 7-azaindole analogues in which the structural information is well documented.
\end{abstract}

\section{Introduction}

The excited-state double proton transfer (ESDPT) $)^{1-3}$ in the 7-azaindole (7AI) dimer (Figure 1) has long been recognized as a prototype to mimic the photoinduced mutation of the DNA base pair. ${ }^{4,5}$ Much research has focused on the dynamics of ESDPT, especially in solution phase.$^{6-10}$ Early studies have revealed that the rate of proton transfer is within $0.3-1.0 \times$ $10^{12} \mathrm{~s}^{-1}$ for the 7AI dimer in nonpolar solvents. ${ }^{6,7}$ Recently, 0.2 -ps and 1.1-ps dynamics were resolved by Takeuchi and Tahara $^{8}$ and first assigned to the rates of internal conversion and proton transfer, respectively, based on a concerted ESDPT model. Subsequently, Chachisvilis et al. ${ }^{9}$ reported the 1-ps and 12-ps dynamics and interpreted on the basis of nonconcerted double proton-transfer reaction, but it was then claimed that the 12-ps component is due to the vibrational cooling. ${ }^{10}$ Then, Fiebig et al. reassigned the 0.2-ps and 1-ps components to the two-steps double proton transfer ${ }^{11}$ and concluded that both trajectories of the symmetric and asymmetric vibrational motion coupled with the solvent dynamics must be considered for the ESDPT in the solution phase. Only when the internal energy is small, such as at sufficiently low temperatures, can one examine the process of tunneling and nonconcertedness. Despite different viewpoints on the mechanism, both claimed observation of the kinetic isotope effects on the rate of ESDPT at ambient temperature.

Temperature-dependent ESDPT dynamics on 7AI were once suggested to be inaccessible due to the formation of thermodynamically more favorable oligomers at low temperature. ${ }^{12,13}$

\footnotetext{
* To whom correspondence should be addressed.

${ }^{\dagger}$ Department of Chemistry, National Chung-Cheng University.

Department of Chemistry, Fu Jen Catholic University.

$\S$ Department of Chemistry, National Taiwan University.
}

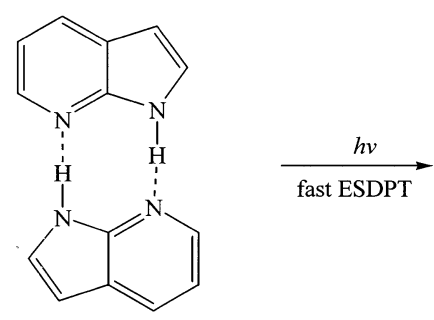<smiles></smiles>

a tautomer emission $\left(\lambda_{\max } \sim 480 \mathrm{~nm}\right)$

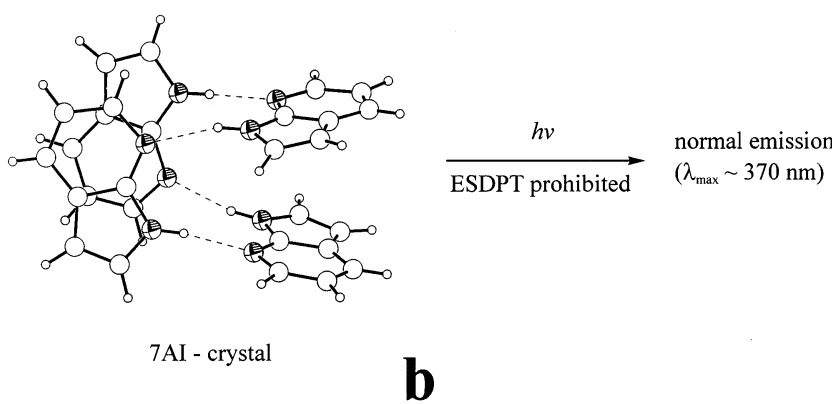

Figure 1. Differences in photophysical properties for the 7AIassociated structures: a. the dual hydrogen-bonded dimer (in solution) and $b$. tetrameter (in a single crystal).

In a $77 \mathrm{~K}$ methylcyclohexane glass containing concentrated 7AI, the dominant steady-state emission maximum at $\sim 460 \mathrm{~nm}$ was reported to originate from phosphorescence of the oligomers in which the cooperative double proton transfer is prohibited. ${ }^{12,13}$ Recently, via a clever approach of applying sufficiently low 7AI concentrations, Catalán and Kasha ${ }^{14}$ were able to resolve the dimeric form at low temperature and to study its corre- 
<smiles>Cc1c[nH]c2ncccc12</smiles>

3MAI (normal form)<smiles>Cc1cn(C)c2ncccc12</smiles>

3MM(1)AI

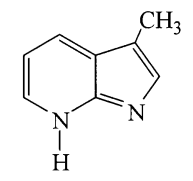

3MAI (tautomer form)

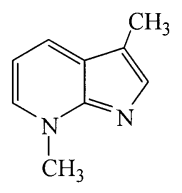

$3 \mathrm{MM}(7) \mathrm{AI}$

Figure 2. Structures of $3 \mathrm{MAI}$ and their corresponding proton-transfer isomer as well as methylated derivatives.

sponding proton-transfer spectroscopy. Instead of the exclusive proton-transfer tautomer fluorescence in the 7AI dimer, the appearance of normal dimeric fluorescence at $<200 \mathrm{~K}$ for the deuterated 7AI rendered a convincing deuterium isotope effect on the ESDPT dynamics ${ }^{14}$ (hereafter N(1)-protonated and deuterated-7AI analogues are denoted by the suffix $-h$ and $-d$, respectively). However, from the thermodynamic point of view, the hydrogen-bonding equilibrium should be dominated by the enthalpic factor and hence favors the oligomer formation at sufficiently low temperatures (e.g., $77 \mathrm{~K}$ and lower). It is thus rather difficult to determine the lower-limit temperature at which the existence of dual hydrogen-bonded dimer is free from the interference of oligomers. This in combination with possible perturbations resulting from solvent dielectric relaxation and/ or viscosity (e.g., solvent cage) may further smear and complicate the ESDPT dynamics.

From yet another approach, the hydrogen bond in the solid state can be well-characterized. ${ }^{15}$ It has been demonstrated that the hydrogen-bonding structure in the single crystal provides an ideal model for investigating proton-transfer dynamics free from the solvent perturbation. ${ }^{16,17}$ Unfortunately, the crystal structure of 7AI reveals tetrameric units of approximate $S_{4}$ symmetry, in which molecules are associated by means of four complementary $\mathrm{N}-\mathrm{H} \cdot \cdots \mathrm{N}$ hydrogen bonds ${ }^{18}$ (Figure 1b). As a result the cooperative ESDPT is prohibited. Recently, we have found that chemical modification at the $\mathrm{C}(3)$-position of 7AI, forming 3-iodo-7-azaindole (3IAI), exhibited a dimeric structure in the single crystal. Steady-state approaches have shown the dominant ESDPT process even at $10 \mathrm{~K}$ for the 3IAI- $h$ dimer, resulting in a unique tautomer emission. ${ }^{19}$ Unfortunately, studies on ESDPT dynamics of 3IAI, particularly the deuterium isotope effect, were rather difficult due to its photochemical liability as well as fast $S_{1}-T_{1}$ intersystem crossing enhanced by the iodine heavy atom effect. ${ }^{19,20}$ Thus, chemical modifications on 7AI suitable for investigating intrinsic ESDPT in the singlecrystal became one of our focuses. In this study 3-methyl-7azaindole (3MAI, Figure 2) was synthesized, of which the photostability is superior to that of 3IAI. Furthermore, unlike 3IAI where the association of iodine substituents induces strong perturbation due to the enhanced spin-orbit coupling and resonance effects, the much more inert methyl substitution in 3MAI provides an ideal model to mimic the intrinsic ESDPT dynamics of the 7AI dimer.

\section{Experimental Section}

2.1. Materials. Synthesis of 3-methyl-7-azaindole (3MAI). A precursor 7-azaindole-3-carboxaldehyde has to be prepared prior to the synthesis of 3MAI, which was synthesized according to the previous report. ${ }^{21}$ Subsequently, a solution of semicarbazide hydrochloride $(1.35 \mathrm{~g})$ and sodium acetate trihydrate $(2.3 \mathrm{~g})$ was added to a solution containing 7-azaindole-3-carboxaldehyde $(0.80 \mathrm{~g})$ in $80 \mathrm{~mL}$ of boiling water. After the appearance of a transitory yellow coloration, a white solid gradually precipitated. The mixture was then heated on the steam-bath for $\sim 15 \mathrm{~min}$, then cooled to yield semicarbazone $(1.1 \mathrm{~g})$. Semicarbazone $(1.1 \mathrm{~g})$ was added to a solution containing sodium $(0.96 \mathrm{~g})$ in dry diethylene glycol $(40 \mathrm{~mL})$. The solution was refluxed at $205^{\circ} \mathrm{C}$ under nitrogen atmosphere for $1 \mathrm{~h}$, and the mixture was cooled and poured into $\sim 230 \mathrm{~mL}$ of water containing $3.1 \mathrm{~g}$ of glacial acetic acid. The resulting solution, which contained solid in suspension, was extracted with ether. The extracts were then washed with water, dried, and evaporated. The crude product was chromatographed on silica gel (eluent: ethyl acetate) to obtain $0.41 \mathrm{~g}(55 \%)$ 3MAI. ${ }^{1} \mathrm{H}$ NMR (400 MHz), $\delta 9.66(\mathrm{~s}, 1 \mathrm{H}), 8.28$ (dd, $J=1.6,4.8 \mathrm{~Hz}, 1 \mathrm{H})$, $7.89(\mathrm{dd}, J=1.4,7.6 \mathrm{~Hz}, 1 \mathrm{H}), 7.08(\mathrm{~s}, 1 \mathrm{H}), 7.04(\mathrm{dd}, J=4.4$, $8.0 \mathrm{~Hz}, 1 \mathrm{H}), 2.31(\mathrm{~s}, 3 \mathrm{H})$. A single crystal of 3MAI- $h$ with dimensions of $\sim 0.50 \times 0.45 \times 0.45 \mathrm{~mm}^{3}$ was obtained by slow evaporation in a $\mathrm{CH}_{3} \mathrm{OH}$ solution. To obtain the $3 \mathrm{MAI}-d$ single crystal, a similar recrystalization procedure was repeated three times in the $\mathrm{CD}_{3} \mathrm{OD}$ solution under the $\mathrm{N}_{2}$ atmosphere. After monitoring the disappearance of the $\mathrm{N}(1)-\mathrm{H}$ proton in ${ }^{1} \mathrm{H} \mathrm{NMR}$ (in $\mathrm{CDCl}_{3}$ ), we concluded that $\sim 95 \%$ of the $\mathrm{N}-\mathrm{H}$ proton had been deuterated. The transfer of $3 \mathrm{MAI}-d$ to the cryostat was handled in a $\mathrm{N}_{2}$ filled drybox to avoid the $\mathrm{D} / \mathrm{H}$ exchange on the surface of the crystal.

The compound 1,3-dimethyl-7-azaindole (3MM(1)AI, Figure 2) was synthesized by adding sodium hydride $(57 \%, 60 \mathrm{mg})$ to the THF solution containing 3MAI $(0.15 \mathrm{~g})$, followed by the addition of methyl iodide (30 mg). ${ }^{1} \mathrm{H} \mathrm{NMR}\left(\mathrm{CDCl}_{3}, 400 \mathrm{MHz}\right)$, $\delta 2.32(\mathrm{~s}, 3 \mathrm{H}), 4.10(\mathrm{~s}, 3 \mathrm{H}), 7.0(\mathrm{~s}, 1 \mathrm{H}), 7.17(\mathrm{t}, 1 \mathrm{H}), 8.05(\mathrm{~d}$, $J=7.2 \mathrm{~Hz}, 1 \mathrm{H}), 8.33(\mathrm{~d}, J=5.2 \mathrm{~Hz}, 1 \mathrm{H})$. The compound 3,7-dimethyl- $1 H$-pyrrolo[2,3- $b$ ]pyridine (3MM(7)AI, Figure 2) was synthesized by the reaction of $3 \mathrm{MAI}(0.12 \mathrm{~g})$ and $\mathrm{CH}_{3} \mathrm{I}$ $(0.58 \mathrm{~g})$ in THF under a $\mathrm{N}_{2}$ atmosphere. $\mathrm{NaOH}(2.5 \mathrm{~N}, 3 \mathrm{~mL})$ was then added and the mixture was stirred for $\sim 20 \mathrm{~min}$ to obtain 3MM(7)AI (60 mg). ${ }^{1} \mathrm{H}$ NMR $\left(\mathrm{CDCl}_{3}, 400 \mathrm{MHz}\right), \delta 2.37$ $(\mathrm{s}, 3 \mathrm{H}), 4.74(\mathrm{~s}, 3 \mathrm{H}) ; 7.37(\mathrm{t}, 1 \mathrm{H}) ; 7.55(\mathrm{~s}, 1 \mathrm{H}) ; 7.98(\mathrm{~d}, J=7.64$ $\mathrm{Hz}, 1 \mathrm{H}) ; 8.34(\mathrm{~d}, J=6.8 \mathrm{~Hz}, 1 \mathrm{H})$.

2.2. Measurements. A closed-helium-cycle cryostat (Oxford, Model CCC1104) was used for the temperature-dependent study in the range of $298-8 \mathrm{~K}$. The solid sample (i.e., single crystal) was placed tightly between two thin quartz plates that came into close contact with the Indium part of the cooling compartment to ensure maximum thermal conduction. The solid sample was excited by the fourth harmonic $(266 \mathrm{~nm})$ of the Nd:YAG laser under a front-face configuration. The resulting fluorescence was detected by an intensified charge coupled detector (ICCD, Princeton Instrument, Model 576G/1) coupled with a polychromator in which the grating is blazed with a maximum of 500 $\mathrm{nm}$. Occasionally, to obtain excitation spectra the output of an Nd:YAG (355 nm, 8 ns, Continuum Surlite II) pumped optical parametric oscillator was tuned between 650 and $720 \mathrm{~nm}$ and was then frequency doubled by a BBO crystal to obtain a tunable 325-360 nm excitation frequency. The intensity of the laser pulse was measured by a joule meter, which was then normalized to obtain the corrected excitation spectra. A combination of filters was used in front of the exit polychromator to isolate the emission wavelengths of interest. The crystal orientation was $45^{\circ}$ with respect to the direction of the excitation light.

Detailed fluorescence lifetime measurement has been described in the previous report. ${ }^{22}$ Briefly, a third harmonic of the Ti-Sapphire oscillator (100 fs, $82 \mathrm{MHz}$, Spectra Physics) 

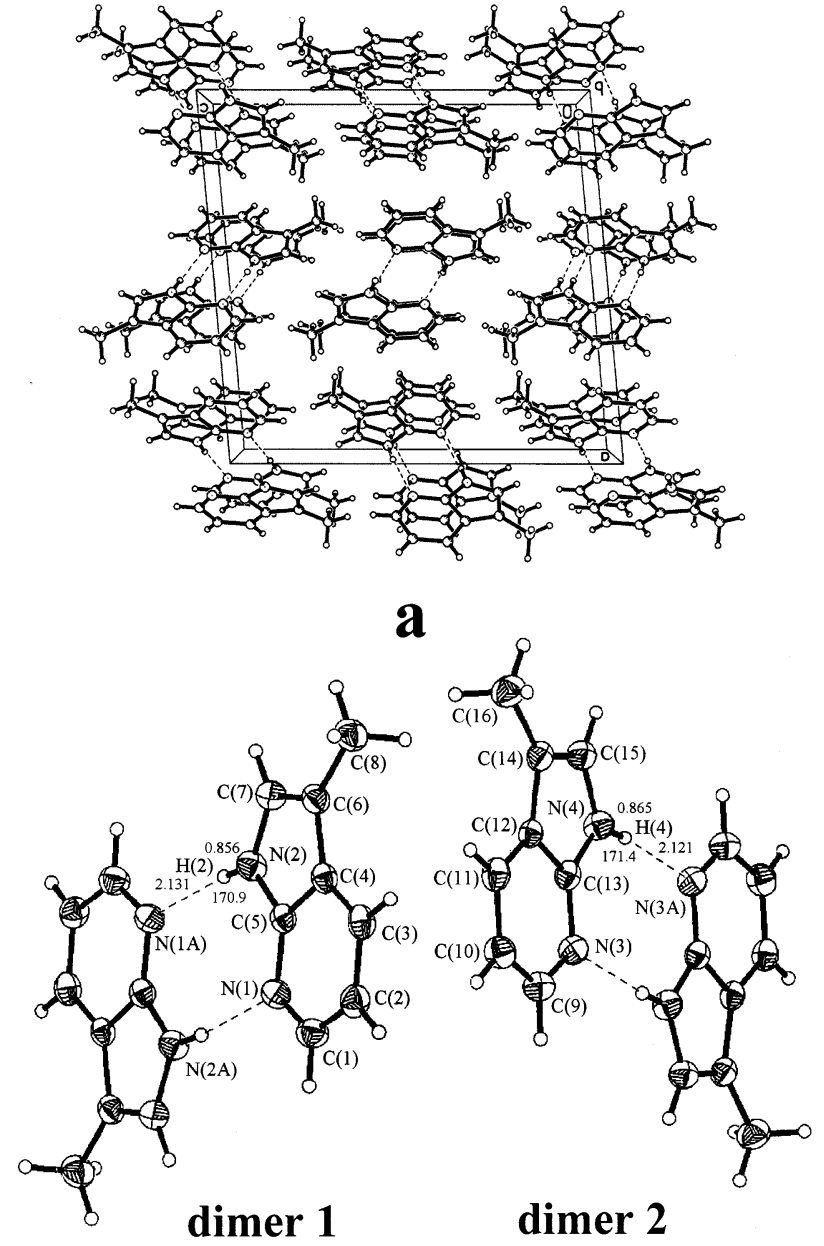

b

Figure 3. a. The projection of $3 \mathrm{MAI}-h$ dimer in a unit cell of the single crystal. b. Two types of spatially arranged dimeric forms, specified as dimer $\mathbf{1}$ and $\mathbf{2}$. Bond distance and angle are in angstroms and degree (degrees), respectively.

coupled with a pulse picker (NEOS, model N17389) was used as an excitation source, giving a tunable wavelength in the range of 255-275 $\mathrm{nm}$ with a repetition rate of $8 \mathrm{MHz}$. An Edinburgh OB 900-L single-photon counter was used as a detecting system. The resolution of the time-correlated photon-counting system is limited by the detector response of $\sim 30 \mathrm{ps}$. The fluorescence decays were analyzed by the sum of exponential functions with an iterative convolution method reported previously, ${ }^{23}$ which allows partial removal of the instrument time broadening and consequently renders a temporal resolution of $\sim 15 \mathrm{ps}$.

\section{Results}

3.1. Structure of 3MAI in a Single Crystal. As shown in Figure 3, the crystal structure of 3MAI- $h$ is composed of a cyclic dimer via dual $\mathrm{N}-\mathrm{H} \cdots \mathrm{N}$ hydrogen bonds. Parallel cyclic dimers are stacked via the interaction between their ring $\pi$-systems to form alternating slabs. The orientation of the parallel molecules in one slab is nearly perpendicular to those in adjacent slabs. The space group is $p 2_{1} / C$, and $Z=8$. Thus, there are two kinds of crystallographically independent molecules. Each of them forms a hydrogen-bonding dimer by the operation of the inversion center, while there is no symmetry relation between the two forms of dimers. To examine whether these two kinds

TABLE 1: Bond Lengths [Ångstroms] and Angle [Degrees] for 3MAI-h in a Single Crystal

\begin{tabular}{lrlr}
\hline & \multicolumn{3}{c}{ Dimer 1 } \\
$\mathrm{N}(1)-\mathrm{C}(5)$ & $1.332(2)$ & $\mathrm{N}(1)-\mathrm{C}(1)$ & $1.335(2)$ \\
$\mathrm{N}(2)-\mathrm{C}(5)$ & $1.365(2)$ & $\mathrm{N}(2)-\mathrm{C}(7)$ & $1.368(2)$ \\
$\mathrm{C}(1)-\mathrm{C}(2)$ & $1.387(2)$ & $\mathrm{C}(2)-\mathrm{C}(3)$ & $1.377(2)$ \\
$\mathrm{C}(3)-\mathrm{C}(4)$ & $1.394(2)$ & $\mathrm{C}(4)-\mathrm{C}(5)$ & $1.416(2)$ \\
$\mathrm{C}(4)-\mathrm{C}(6)$ & $1.425(2)$ & $\mathrm{C}(6)-\mathrm{C}(7)$ & $1.367(2)$ \\
$\mathrm{C}(6)-\mathrm{C}(8)$ & $1.502(2)$ & $\mathrm{N}(2)-\mathrm{H}(2)$ & $0.856(2)$ \\
$\mathrm{N}(1 \mathrm{~A}) \cdots \mathrm{H}(2)$ & $2.131(2)$ & $\mathrm{N}(1 \mathrm{~A}) \cdots \mathrm{N}(2)$ & $2.980(2)$ \\
$\mathrm{C}(5)-\mathrm{N}(1)-\mathrm{C}(1)$ & $113.95(14)$ & $\mathrm{C}(5)-\mathrm{N}(2)-\mathrm{C}(7)$ & $108.30(14)$ \\
$\mathrm{N}(1)-\mathrm{C}(1)-\mathrm{C}(2)$ & $124.99(16)$ & $\mathrm{C}(3)-\mathrm{C}(2)-\mathrm{C}(1)$ & $119.98(16)$ \\
$\mathrm{C}(2)-\mathrm{C}(3)-\mathrm{C}(4)$ & $117.77(15)$ & $\mathrm{C}(3)-\mathrm{C}(4)-\mathrm{C}(5)$ & $116.74(14)$ \\
$\mathrm{C}(3)-\mathrm{C}(4)-\mathrm{C}(6)$ & $135.71(15)$ & $\mathrm{C}(5)-\mathrm{C}(4)-\mathrm{C}(6)$ & $107.54(14)$ \\
$\mathrm{N}(1)-\mathrm{C}(5)-\mathrm{N}(2)$ & $125.88(14)$ & $\mathrm{N}(1)-\mathrm{C}(5)-\mathrm{C}(4)$ & $126.57(14)$ \\
$\mathrm{N}(2)-\mathrm{C}(5)-\mathrm{C}(4)$ & $107.54(14)$ & $\mathrm{C}(7)-\mathrm{C}(6)-\mathrm{C}(4)$ & $105.41(14)$ \\
$\mathrm{C}(7)-\mathrm{C}(6)-\mathrm{C}(8)$ & $128.49(16)$ & $\mathrm{C}(4)-\mathrm{C}(6)-\mathrm{C}(8)$ & $126.10(15)$ \\
$\mathrm{C}(6)-\mathrm{C}(7)-\mathrm{N}(2)$ & $111.22(15)$ & $\mathrm{N}(1 \mathrm{~A}) \cdots \mathrm{H}(2)-\mathrm{N}(2)$ & 170.90
\end{tabular}

$\mathrm{N}(3)-\mathrm{C}(13)$

$\mathrm{N}(4)-\mathrm{C}(13)$

$\mathrm{C}(9)-\mathrm{C}(10)$

$\mathrm{C}(11)-\mathrm{C}(12)$

$\mathrm{C}(12)-\mathrm{C}(14)$

$\mathrm{C}(14)-\mathrm{C}(16)$

$\mathrm{N}(3 \mathrm{~A}) \cdots \mathrm{H}(4)$

$\mathrm{C}(13)-\mathrm{N}(3)-\mathrm{C}(9)$

$\mathrm{N}(3)-\mathrm{C}(9)-\mathrm{C}(10)$

$\mathrm{C}(10)-\mathrm{C}(11)-\mathrm{C}(12)$

$\mathrm{C}(11)-\mathrm{C}(12)-\mathrm{C}(14)$

$\mathrm{N}(3)-\mathrm{C}(13)-\mathrm{N}(4)$

$\mathrm{N}(4)-\mathrm{C}(13)-\mathrm{C}(12)$

$\mathrm{C}(15)-\mathrm{C}(14)-\mathrm{C}(16)$

$\mathrm{C}(14)-\mathrm{C}(15)-\mathrm{N}(4)$
Dimer 2

$1.335(2) \quad \mathrm{N}(3)-\mathrm{C}(9)$

$1.366(2) \quad \mathrm{N}(4)-\mathrm{N}(15)$

$1.390(2) \quad \mathrm{C}(10)-\mathrm{C}(11)$

$1.386(2) \quad \mathrm{C}(12)-\mathrm{C}(13)$

$1.434(2) \quad \mathrm{C}(14)-\mathrm{C}(15)$

$1.500(2) \quad \mathrm{N}(4)-\mathrm{H}(4)$

$2.121(2) \quad \mathrm{N}(3 \mathrm{~A}) \cdots \mathrm{N}(4)$

$113.75(14) \quad \mathrm{C}(13)-\mathrm{N}(4)-\mathrm{C}(15)$

125.03(16) $\quad C(11)-C(10)-C(9)$

$117.89(15) \quad C(11)-C(12)-C(13)$

135.84(14) $C(13)-C(12)-C(14)$

$125.77(14) \quad \mathrm{N}(3)-\mathrm{C}(13)-\mathrm{C}(12)$

107.71(14) $\mathrm{C}(15)-\mathrm{C}(14)-\mathrm{C}(12)$

$128.67(17) \quad C(12)-C(14)-C(16)$

$111.16(15) \quad \mathrm{N}(3 \mathrm{~A}) \cdots \mathrm{H}(4)-\mathrm{N}(4)$
$1.335(2)$

$1.368(2)$

$1.376(2)$

$1.415(2)$

$1.365(2)$

$0.865(2)$

$2.979(2)$

$108.42(14)$

$119.82(15)$

$117.01(14)$

$107.15(13)$

$126.50(14)$

$105.55(14)$

$125.77(15)$

of hydrogen-bonding dimers (specified as dimer $\mathbf{1}$ and dimer 2) are in the same circumstances in the single crystal, we have closely examined these two components in the X-ray data. The results of X-ray structural analyses are shown in Figure 3 and Table 1. The sameness in configuration of these two hydrogenbonded dimers under different spatial arrangements can be supported by several critical bond lengths and angles shown in Table 1. For example, $\mathrm{N}(1 \mathrm{~A}) \cdots \mathrm{N}(2)$ and $\mathrm{N}(1 \mathrm{~A}) \cdots \mathrm{H}(2) \mathrm{N}(2)$ were calculated to be 2.980 and $2.131 \AA$, respectively, for dimer 1 . In addition, the angle of $\mathrm{N}(1 \mathrm{~A}) \cdots \mathrm{H}(2) \mathrm{N}(2)$ was calculated to be $170.9^{\circ}$. In comparison, similar results of $2.979 \AA$ (N(3A) * $\cdot \mathrm{N}(4))$ and $2.121 \AA(\mathrm{N}(3 \mathrm{~A}) \cdot \cdot \mathrm{H}(4) \mathrm{N}(4))$ with an $\mathrm{N}(3 \mathrm{~A}) \cdot \cdot \mathrm{H}(4) \mathrm{N}$ (4) angle of $171.4^{\circ}$ were obtained for dimer 2 . These, in combination with similar bond angles and bond distances among the rest of the atoms between dimer $\mathbf{1}$ and $\mathbf{2}$ (see Table 1) indicate that within the standard deviation these two hydrogenbonding dimers are in the same configuration and hence should behave in practically the same way.

To ensure the same crystal structure in both fluorescence and $\mathrm{X}$-ray measurements, we first determined the structure by X-ray spectroscopy, followed by performing temperature-dependent fluorescence spectroscopy and dynamics of the same single crystal. During the fluorescence measurement an ultrahigh vacuum was maintained in the cryostat so that the $\mathrm{D} / \mathrm{H}$ isotope exchange was negligible. In the case of 3MAI- $d$, great care was taken to perform the X-ray measurement in dry air conditions, and the results are attached in the Supporting Information. Comparing X-ray data shown in Table 1 and Supporting Information, it is obvious that single crystals of 3MAI- $h$ and $3 \mathrm{MAI}-d$ used in the fluorescence studies are isomorphous. The $\mathrm{X}$-ray crystallography was also performed at $-80^{\circ} \mathrm{C}$. The results showed negligible differences in structure from that obtained at $295 \mathrm{~K}$, indicating no temperature-dependent structural transformation for 3MAI in a single crystal. 


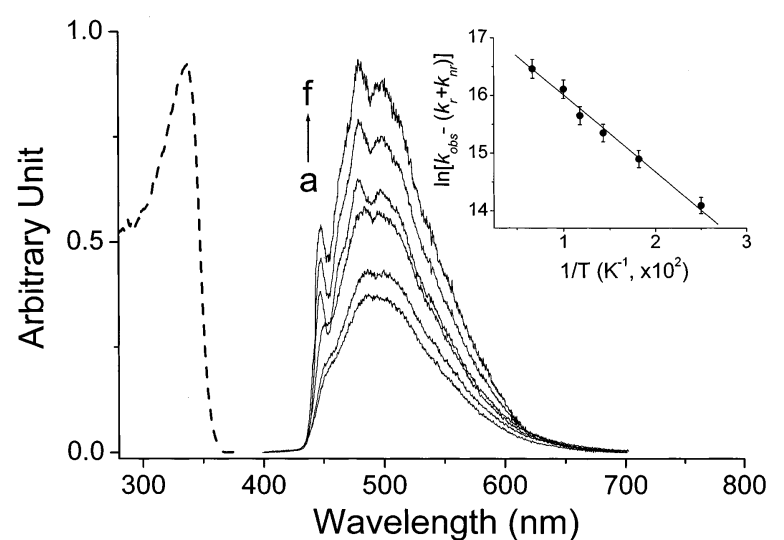

Figure 4. (-) The fluorescence of the $3 \mathrm{MAI}-h$ crystal as a function of temperature at a. 298 , b. 240 , c. 195 , d. 90 , e. 50 , and f. 8 K. (- $)$ The absorption spectra of 3MAI- $h$ in a solid form at room temperature. Inset: The plot of $\ln \left[k_{\mathrm{obs}}-\left(k_{\mathrm{r}}+k_{\mathrm{nr}}\right)\right]$ versus the reciprocal of the temperature.

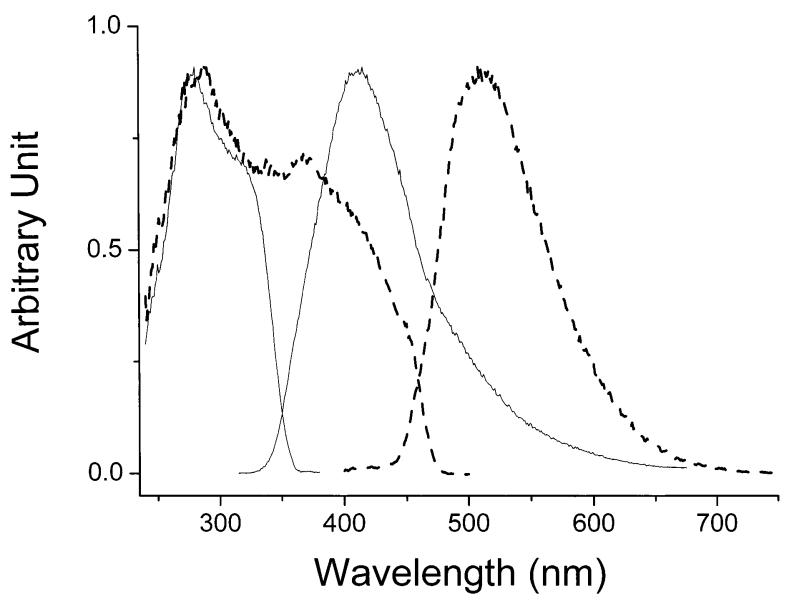

Figure 5. The fluorescence and fluorescence excitation spectra of $3 \mathrm{MM}(1) \mathrm{AI}(-)$ and $3 \mathrm{MM}(7) \mathrm{AI}(-)$ in the crystal form at ambient temperature.

3.2. Spectroscopy and Dynamics in the Single Crystal. In contrast to a normal fluorescence $\left(\lambda_{\max } \sim 370 \mathrm{~nm}\right)$ observed in 7AI, ${ }^{19}$ 3MAI- $h$ in a single crystal exhibited a unique, large Stokes-shifted fluorescence $\left(\lambda_{\max } \sim 500 \mathrm{~nm}\right)$ throughout $298-$ 8.0 K (Figure 4). In comparison, 3MM(1)AI (see Figure 2), which serves as a nonproton-transfer model for 3MAI, revealed a fluorescence with a peak maximum at $410 \mathrm{~nm}\left(\tau_{\mathrm{f}} \sim 0.9 \mathrm{~ns}\right)$ in the solid state. Conversely, 3MM(7)AI, a model compound of the proton-transfer tautomer, exhibited room-temperature fluorescence maximized at $510 \mathrm{~nm}$ (Figure 5, $\tau_{\mathrm{f}} \sim 2.1 \mathrm{~ns}$ ), of which the spectral and dynamical features resemble those observed in the 3MAI- $h$ single crystal. These steady-state approaches unambiguously lead to two concluding remarks: 1 . ESDPT is apparently operative in the $3 \mathrm{MAI}-h$ single crystal, resulting in a 500-nm proton-transfer tautomer emission. 2. Due to the lack of any observable normal emission, the rate of ESDPT must be fast even at a temperature of as low as $8.0 \mathrm{~K}$. The latter viewpoint was supported by the subsequent timeresolved measurement. When monitored at the 500-nm emission band, the rise component of the tautomer fluorescence was too fast to be resolved ( $\ll 15 \mathrm{ps}$ ) throughout $298-8.0 \mathrm{~K}$. Conversely, the decay of the tautomer emission can be well fitted by single exponential kinetics. The lifetime-revealed slight temperature dependence, varying from 2.7 (298 K) to $7.4 \mathrm{~ns}$ $(8.0 \mathrm{~K})$. From the standpoint of a temperature-independent

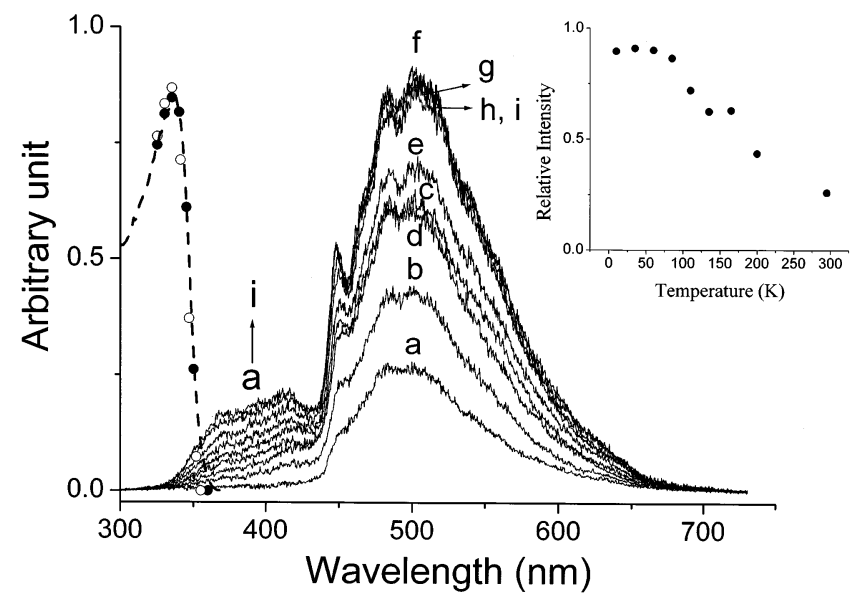

Figure 6. (-) The fluorescence of $3 \mathrm{MAI}-d$ crystal as a function of temperature at a. 298 , b. 200 , c. 165 , d. 135 , e. 110 , f. 85 , g. 35 , h. 12 , and i. $8 \mathrm{~K}$. The excitation spectrum of the $3 \mathrm{MAI}-d$ crystal monitored at the $\mathrm{F}_{2}(\bullet \bullet)$ and $\mathrm{F}_{1}$ bands (o o). The excitation wavelength was tuned from 360 to $325 \mathrm{~nm}$. (- -) The absorption spectra of 3MAI- $d$ in a solid form at room temperature. Inset: The plot of tautomer emission intensity at $500 \mathrm{~nm}$ versus the temperature (in Kelvin).

fluorescence radiative decay rate, the result simply indicates the decrease in nonradiative deactivation rates (vide infra), which is consistent with the steady-state measurement, showing that the intensity of the tautomer emission increased as the temperature decreased (see Figure $4 a-f$ ).

Remarkable temperature-dependent fluorescence spectra were observed for the 3MAI- $d$ single crystal. Dual emission became obvious at $<200 \mathrm{~K}$, in which a normal emission band (specified as the $\mathrm{F}_{1}$ band) maximized at $395 \mathrm{~nm}$ gradually appeared (Figure 6). Conversely, the 500-nm tautomer emission (specified as the $\mathrm{F}_{2}$ band) intensity versus temperature was slightly irregular (see insert of Figure 6); it increased upon decreasing the temperature from 298 to $190 \mathrm{~K}$, followed by a decrease in the intensity at $150-120 \mathrm{~K}$. At $<12 \mathrm{~K}$ the intensity as well as the ratio of dual emission was nearly temperature independent. By tuning the excitation wavelength, the resulting excitation spectrum, within experimental error, was independent of the emission wavelength monitored at either the $\mathrm{F}_{1}$ or $\mathrm{F}_{2}$ band, which is also effectively identical with the absorption profile (see Figure 6).

In accordance with the steady-state approach, a remarkable deuterium isotope effect on the ESDPT dynamics was also observed in the 3MAI- $d$ single crystal. While the rise component of the $\mathrm{F}_{1}$ band was beyond the instrument response of $\sim 15 \mathrm{ps}$ at $298-8.0 \mathrm{~K}$, at $<150 \mathrm{~K}$ the decay was resolvable and revealed drastic temperature dependence. As shown in Figure 7A and Table 2, the results clearly showed a decrease of the singleexponential decay rate constant, $k_{\mathrm{obs}}{ }^{\mathrm{N}}$, upon decreasing the temperature. For instance, $k_{\mathrm{obs}}{ }^{\mathrm{N}}$ measured to be $3.8 \times 10^{9} \mathrm{~s}^{-1}$ at $8 \mathrm{~K}$ is smaller than that of $2.6 \times 10^{10} \mathrm{~s}^{-1}$ measured at 100 $\mathrm{K}$ by $\sim 7$-fold. Conversely, the fluorescence dynamics of the $\mathrm{F}_{2}$ band resolved at $<150 \mathrm{~K}$ could only be fitted by dual exponential kinetics, which consist of a rise and a decay component as indicated by the fitted negative and positive preexponential factors, respectively. When monitored at $>520$ $\mathrm{nm}$ region free from the interference of the normal emission, the absolute values for both rise and decay preexponential factors, within experimental error, are similar (see Table 2). Slight differences are possibly attributed to the existence of $\sim 5 \%$ of nondeuterated 3MAI- $h$ in which fast ESDPT takes place. Therefore, the fitted preexponential value for the decay component is greater than that for the rise component. Table 2 also 

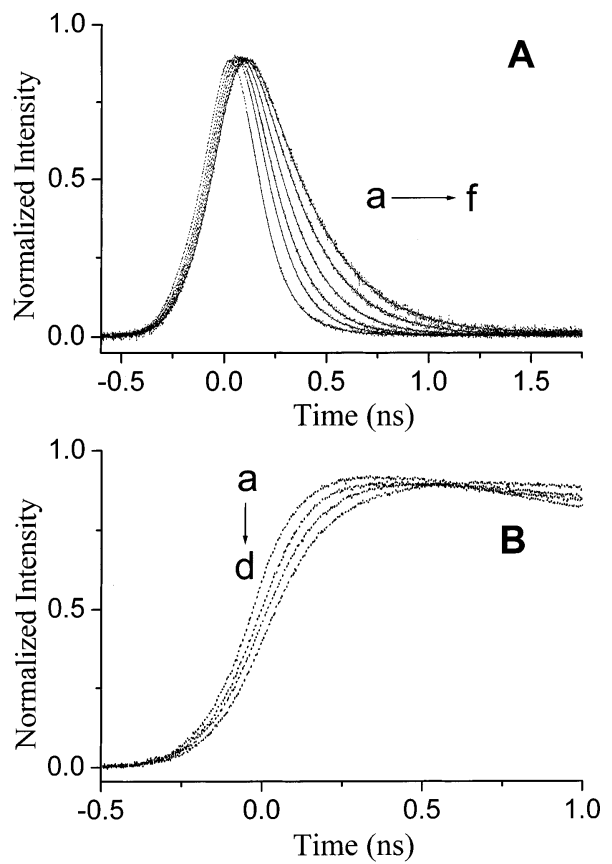

Figure 7. A. The time-dependent fluorescence decay dynamics of the $3 \mathrm{MAI}-d$ crystal monitored at the $\mathrm{F}_{1}$ band $(380 \mathrm{~nm})$ at various temperatures of a. 150 , b. 100 , c. 70 , d. 40 , e. 20 , and f. $10 \mathrm{~K}$. B. The rise dynamics of the $\mathrm{F}_{2}$ band $(520 \mathrm{~nm})$ monitored at a. 190, b. 150, c. 70 , and d. $10 \mathrm{~K}$.

TABLE 2: Temperature-Dependent Fluorescence Relaxation Dynamics for 3MAI- $d$ in a Single Crystal

\begin{tabular}{cccccc}
\hline & \multicolumn{5}{c}{ fluorescence lifetime } \\
\cline { 2 - 6 } temperature & $\mathrm{F}_{1}\left(\lambda_{\max }=395 \mathrm{~nm}\right)$ & \multicolumn{4}{c}{$\mathrm{F}_{2}\left(\lambda_{\max }=500 \mathrm{~nm}\right)^{a}$} \\
\cline { 2 - 6 } & $\tau(\mathrm{ns})$ & $\tau_{1}(\mathrm{~ns})$ & $a_{1}$ & $\tau_{2}(\mathrm{~ns})$ & $a_{2}$ \\
\hline 150 & $\mathrm{NA}$ & & & 6.66 & 1.000 \\
100 & 0.038 & 0.040 & -0.208 & 6.80 & 0.239 \\
70 & 0.061 & 0.060 & -0.205 & 7.15 & 0.235 \\
40 & 0.127 & 0.130 & -0.010 & 7.28 & 0.014 \\
20 & 0.210 & 0.226 & -0.011 & 7.33 & 0.017 \\
10 & 0.260 & 0.260 & -0.011 & 7.36 & 0.013 \\
8 & 0.263 & 0.265 & -0.011 & 7.38 & 0.015
\end{tabular}

${ }^{a}$ The $\mathrm{F}_{2}$ band was fitted by dual exponential kinetics expressed as $F(t)=a_{1} \mathrm{e}^{-\tau_{1}^{-1} t}+a_{2} \mathrm{e}^{-\tau_{2}^{-1} t}$.

shows an interesting correlation between decay and rise components for the $F_{1}$ and $F_{2}$ bands, respectively, at various temperatures, in which the rise time of the $F_{2}$ band, within experimental error, was the same as the decay time of the $F_{1}$ band. In summary, the time-resolved measurement in combination with steady-state approaches led us to conclude that both $F_{1}$ (normal emission) and $F_{2}$ (tautomer emission) bands originate from the same ground-state species, i.e., the normal dimeric form, and the $\mathrm{F}_{1}$ band is apparently the precursor of the $\mathrm{F}_{2}$ band. Thus, the existence of a nonnegligible ESDPT barrier for the $3 \mathrm{MAI}-d$ dimer is apparent, and the deuterium isotope effect becomes significant on the rate of ESDPT at sufficiently low temperatures. The irregular temperature-dependent tautomer emission intensity for 3-MAI- $d$ can thus be rationalized by two competing relaxation processes: 1 . As the temperature decreases, the decrease of the ESDPT rate results in a smaller yield of population to the tautomer state, 2. The tautomer fluorescence quantum yield tends to increase at lower temperature due to the decrease of the rate of radiationless deactivations. Details on the relaxation dynamics will be discussed in the following section.

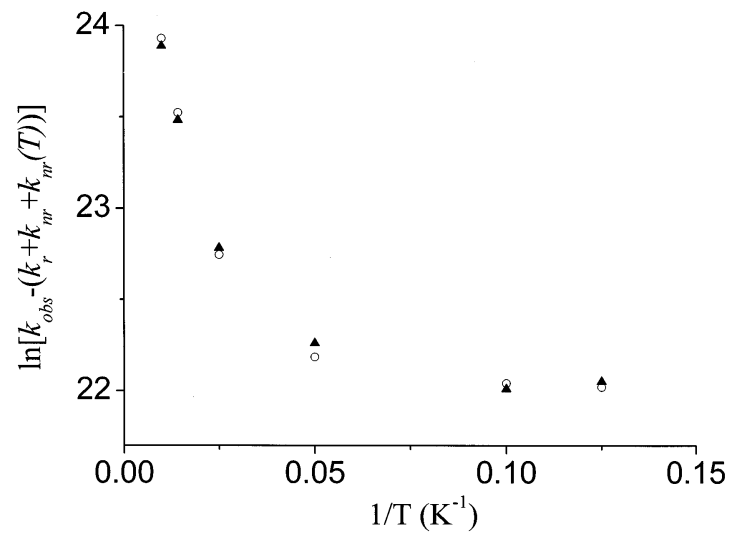

Figure 8. The plot of $\ln \left[k_{\mathrm{obs}}-\left(k_{\mathrm{r}}+k_{\mathrm{nr}}+k_{\mathrm{nr}}(T)\right)\right]$ versus the reciprocal of the temperature for a. the decay of the $F_{1}$ band $(\boldsymbol{\Lambda})$ and b. rise kinetics of the $\mathrm{F}_{2}$ band $(\mathrm{O})$ in a $3 \mathrm{MAI}-d$ single crystal at $\leq 150 \mathrm{~K}$. See text for the definition of $k_{\mathrm{r}}+k_{\mathrm{nr}}+k_{\mathrm{nr}}(T)$.

\section{Discussion}

For the $\mathrm{F}_{2}$ band, the observed temperature-dependent decay rate can be expressed as

$$
k_{\mathrm{obs}}=k_{\mathrm{r}}+k_{\mathrm{nr}}+k_{\mathrm{nr}}(T)
$$

where $k_{\mathrm{nr}}$ denotes the temperature independent radiationless decay rate constant, possibly involving internal conversion, intersystem crossing, etc. The temperature-dependent radiationless decay rate constant $k_{\mathrm{nr}}(T)$ can be further expressed as an Arrhenius type of thermally deactivated pathway, namely, $k_{\mathrm{nr}}{ }^{-}$ $(T)=A \mathrm{e}^{-E_{\mathrm{a}} / R T}$ where $E_{\mathrm{a}}$ is the barrier for the thermally deactivated process. As indicated by the time-resolved measurement, the lifetime of the tautomer emission (the $F_{2}$ band) was invariable at $<12 \mathrm{~K}$. Thus, it is reasonable to assume that $k_{\mathrm{nr}^{-}}$ $(T)$ is negligible, and the decay rate of $1.36 \times 10^{8} \mathrm{~s}^{-1}$ measured at, e.g., $8 \mathrm{~K}$ is equivalent to $k_{\mathrm{r}}+k_{\mathrm{nr}}$. The plot of $\ln \left[k_{\mathrm{obs}}-\left(k_{\mathrm{r}}\right.\right.$ $+k_{\mathrm{nr}}$ )] versus the reciprocal of the temperature reveals straightline behavior (see insert of Figure 4), supporting the validity of the thermal deactivation pathway for the tautomer emission. A best linear least-squares fit for the insert of Figure 4 gives $E_{\mathrm{a}}$ and the frequency factor to be $0.35 \mathrm{kcal} / \mathrm{mol}$ and $5.2 \times 10^{8}$ $\mathrm{s}^{-1}$, respectively.

For the $F_{1}$ band, the observed temperature-dependent decay rate can be expressed as

$$
k_{\mathrm{obs}}=k_{\mathrm{r}}+k_{\mathrm{nr}}+k_{\mathrm{nr}}(T)+k_{\mathrm{pt}}(T)
$$

where $k_{\mathrm{nr}}(T)$ denotes the thermally deactivated pathways except for the rate of proton transfer $k_{\mathrm{pt}}(T)$. It is not feasible to obtain $k_{\mathrm{r}}+k_{\mathrm{nr}}+k_{\mathrm{nr}}(T)$ for the normal emission (i.e., the $\mathrm{F}_{1}$ band) of $3 \mathrm{MAI}$ in a single crystal because the dynamics of relaxation of the excited normal species are still dominated by the rate of double proton-transfer reaction even at low temperatures. Alternatively, we have attempted to obtain $k_{\mathrm{r}}+k_{\mathrm{nr}}+k_{\mathrm{nr}}(T)$ values by performing the temperature-dependent relaxation dynamics of the 3MM(1)AI crystal in which the excited-state proton-transfer reaction is prohibited due to the lack of pyrrolic hydrogen. The results showed a slightly temperature-dependent decay rate from $4 \times 10^{8} \mathrm{~s}^{-1}(150 \mathrm{~K})$ to $1.1 \times 10^{8} \mathrm{~s}^{-1}(8 \mathrm{~K})$. Taking the $k_{\mathrm{obs}}$ value of the $3 \mathrm{MM}(1) \mathrm{AI}$ crystal to be $k_{\mathrm{r}}+k_{\mathrm{nr}}+$ $k_{\mathrm{nr}}(T)$ for the 3MAI- $d$ dimer, a plot of $\ln \left[k_{\mathrm{obs}}-\left(k_{\mathrm{r}}+k_{\mathrm{nr}}+\right.\right.$ $\left.k_{\mathrm{nr}}(T)\right)$ ] versus $1 / T$ is shown in Figure 8. Apparently, the contribution of $k_{\mathrm{r}}+k_{\mathrm{nr}}+k_{\mathrm{nr}}(T)$ is rather small in this plot simply due to its much smaller value in comparison to the rate of double proton-transfer reaction. If the ESDPT dynamics, $k_{\mathrm{pt}}(T)$, mainly 


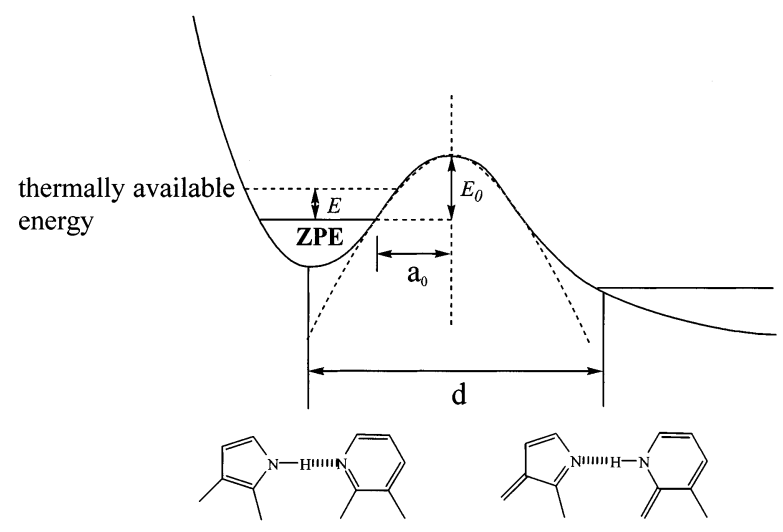

Figure 9. A simplified one-dimensional PES regarding the ESDPT based on a bound-free potential curve. See text for the detailed description of notations.

incorporate a barrier crossing, i.e., a classical thermally activated process, straight-line behavior is expected upon plotting $\ln \left[k_{\mathrm{obs}}\right.$ $\left.-\left(k_{\mathrm{r}}+k_{\mathrm{nr}}+k_{\mathrm{nr}}(T)\right)\right]$ as a function of the reciprocal of the temperature. In contrast, the plot depicted in Figure 8a revealed an asymptote-like curve, which approached a constant value at $<12 \mathrm{~K}$. A similar pattern was also obtained when the rise dynamics of the $\mathrm{F}_{2}$ band (i.e., the tautomer emission) are plotted against the reciprocal of the temperature (see Figure $8 \mathrm{~b}$ ).

The concave asymptote for the $k_{\mathrm{pt}}(T)$-versus-1/T plot in combination with a nearly constant ESDPT rate at 8-12 K led us to conclude that the dynamics of ESDPT for the 3MAI- $d$ crystal are not governed by a thermally activated process, but more plausibly proceed through a proton-tunneling mechanism. To apply such theories, simplified approximation about the ESDPT potential energy surface (PES) is necessary. Both steady-state and dynamic approaches indicate that the ESDPT reaction in the 3MAI dimer is exergonic and irreversible. Accordingly, a simplified one-dimensional PES regarding the ESDPT can be represented by a bound-free potential curve shown in Figure 9, in which the proton-tunneling rate is given by

$$
k_{\text {tunnel }}=v \exp \left[-\frac{\sqrt{2 m}}{\hbar} \int_{-a_{0}}^{a_{0}} V(x)^{1 / 2} \mathrm{~d} x\right]
$$

where $V(x)$ is the energy barrier along the reaction coordinate, $v$ is the bound vibrational frequency, i.e., the reaction-coordinate frequency of the $\mathrm{N}-\mathrm{H}$ (or $\mathrm{N}-\mathrm{D}$ ) mode in the case of 3MAI, $\mathrm{m}$ is the effective mass of the proton or deuterium, and $a_{0}$ is the distance from the center of the barrier to the classical vibrational turning points. Equation 3 can easily be evaluated if the potential barrier is further represented by a semiempirical, one-dimensional approach based on a parabolic shape-like activation energy, i.e., $V(x)=E_{0}\left(1-x^{2} / a_{0}^{2}\right)$ where $E_{0}$ denotes the maximum barrier height above the zero point energy (ZPE). The resolvable ESDPT time scales for 3MAI- $d$ are in the range of few tens to hundreds picoseconds. Thus, it is reasonable to assume a fast thermal equilibrium prior to the ESDPT reaction. Further support of this viewpoint can be given by varying the excitation wavelength from 255 to $275 \mathrm{~nm}$, giving the same results on the ESDPT dynamics (not shown here). Accordingly, the tunneling rate for a molecule possessing thermal energy $\mathrm{E}$ above ZPE can thus be expressed as

$$
k_{\text {tunnel }}=v \exp \left[-\frac{\pi a_{0}}{\hbar} \sqrt{2 m\left(E_{0}-E\right)}\right]
$$

A rough estimate of $a_{0}$ can be obtained from the average $\mathrm{N}-\mathrm{H} \cdots \mathrm{N}$ hydrogen bond distances, ${ }^{24}$ the estimated displacement of the proton transfer (denoted d in Figure 9) and classical turning points for the zero-point motion of the $\mathrm{N}-\mathrm{H}$ (or $\mathrm{N}-\mathrm{D}$ ) harmonic vibration from the equilibrium position. For the case of 7AI, $a_{0}$, has been estimated to be 0.27 and $0.36 \AA$ for $\mathrm{N}(1)-\mathrm{H}$ and $\mathrm{N}(1)-\mathrm{D}$ substituents, respectively. ${ }^{3,11,25}$ The same $a_{0}$ values were used for $3 \mathrm{MAI}$ in the following calculation, assuming that methyl substitution at the $\mathrm{C}(3)$ position has negligible perturbation on the dimeric structure. Since the tunneling rate was measured to be independent of the temperature in the range of 8-12 K, the thermally available energy $\mathrm{E}$ can be neglected. Accordingly, the barrier height $E_{0}$ could be deduced by applying known reaction-coordinate frequency $v$, effective mass $\mathrm{m}$ and the estimated $\mathrm{a}_{0}$ value to eq 4 . For the case of $3 \mathrm{MAI}-d$, taking $v$ to be $\sim 6.0 \times 10^{13} \mathrm{~s}^{-1}\left(\sim 2000 \mathrm{~cm}^{-1}\right)$, an $E_{0}$ value of 605 $\mathrm{cm}^{-1}(1.73 \mathrm{kcal} / \mathrm{mol})$ was thus deduced. At a relatively high temperature such as $>20 \mathrm{~K}$ (see Figure 8 ) the available thermal energy is nonnegligible. The actual tunneling rate has to be calculated by the sum of all possible thermally populated states and is thus complicated. Given the difference in ZPE of $\sim 400$ $\mathrm{cm}^{-1}$ between $\mathrm{N}-\mathrm{H}$ and $\mathrm{N}-\mathrm{D}$ stretching, a barrier height of ESDPT was further deduced to be $\sim 205 \mathrm{~cm}^{-1}(\sim 0.58 \mathrm{kcal} /$ mol) for the 3MAI- $h$ dimer. Plugging $E_{0}$ of $205 \mathrm{~cm}^{-1}, a_{0}{ }^{\mathrm{H}}=$ $0.27 \AA, m=1$, and $v=2800 \mathrm{~cm}^{-1}\left(8.4 \times 10^{13} \mathrm{~s}^{-1}\right)$ to eq 4 , the proton tunneling rate, $k_{\text {tunnel, }}$ was calculated to be $4.3 \times$ $10^{12} \mathrm{~s}^{-1}$ for $3 \mathrm{MAI}-h$ at $<12 \mathrm{~K}$. This time scale of $k_{\text {tunnel }}{ }^{-1}=$ $233 \mathrm{fs}$ is too fast to be resolved by our picosecond timecorrelated single photon counting system. On the basis of the energy barrier of 0.58 and $1.73 \mathrm{kcal} / \mathrm{mol}$, respectively, rates of ESDPT for 3MAI- $h$ and 3MAI- $d$ were calculated to be negligibly small via a thermally activated process at $<12 \mathrm{~K}$.

Certainly, it should be noted that the proton tunneling could rarely be satisfactorily described as a one-dimensional process. The motion of atoms between which the proton is being exchanged may have a major effect on the tunneling rate. ${ }^{26-32}$ Although the above results conclude a finite barrier to ESDPT, it is rather small, and subtle changes in the proton-transfer distance or energetics could have large effects on the protontransfer rates. This recognition has led to the introduction of two-dimensional approaches in which the second dimension represents the effective motion of the other atoms during the proton-transfer reaction. Theoretical approaches ${ }^{33-35}$ have revealed that the KIE (kinetic isotope effect) temperature dependence may be caused by thermally excited reactants and/or products that modulate the barrier width and shape. Although two-dimensional models may produce a more qualitative insight into the kinetic isotope effect and the temperature dependence of the transfer process, they still require the introduction of empirical parameters and thus cannot render quantitative predictions. For more precise quantitative work it is necessary to consider all degrees of freedom of the global system for an overall proton-transfer reaction.

At this stage, we are unable to differentiate the one-step versus two-step, nonconcerted ESDPT mechanism. Although the experimental results indicate a single decay and rise component for normal and tautomer emissions, respectively, it is also possible that ESDPT takes place via a two-step mechanism, and the rate in one of the steps is too fast to be resolved by the picosecond resolution. Alternatively, fluorescence upconversion with femtosecond resolution may provide valuable information. Unfortunately, the temperature-dependent study in the 3MAI single crystal is intrinsically difficult due to the photolysis and/ 
or thermal reaction upon high repetition rate and high power laser excitation. Focus on this subject is currently in progress.

\section{Conclusion}

In conclusion, both steady-state and time-resolved measurements down to $8.0 \mathrm{~K}$ have revealed a remarkable deuterium isotope effect on the rate of ESDPT in the 3MAI- $d$ single crystal. A barrier height of ESDPT of 1.73 and $0.58 \mathrm{kcal} / \mathrm{mol}$ was estimated for the 3MAI- $d$ and 3MAI- $h$ dimers, respectively, in a single crystal, and the ESDPT rates are mainly governed by a proton/deuterium tunneling mechanism. The results provide a prototype to mimic the intrinsic ESDPT dynamics of the 7AIlike dual hydrogen-bonded dimer with complete structural information, which are believed to bring up a broad spectrum of interest in the field of proton-transfer studies.

Acknowledgment. This work was supported by the National Science Council NSC (90-2113-M-002-055).

Supporting Information Available: X-ray data for 3MAI- $h$ and 3MAI- $d$. This material is available free of charge via the Internet at http://pubs.acs.org.

\section{References and Notes}

(1) Taylor, C. A.; El-Bayoumi, M. A.; Kasha, M. Proc. Nat. Acad. Sci. U.S.A. 1969, 63, 253.

(2) Ingham, K. C.; Abu-Elgheit, M.; El-Bayoumi, M. A. J. Am. Chem. Soc. 1971, 93, 5023 1674 .

(3) Ingham. K. C.; El-Bayoumi, M. A. J. Am. Chem. Soc. 1974, 96,

(4) Watson, J. D.; Crick, F. H. C. Nature (London) 1953, 171, 964.

(5) (a) Lowdin, P.-O. Adv. Quantum Chem. 1965, 2, 213. (b) Lowdin, P.-O. Rev. Mod. Phys. 1963, 35, 724.

(6) Hetherington, W. M., III; Micheels, R. H.; Eisenthal, K. B. Chem. Phys. Lett. 1979, 66, 230.

(7) Share, P.; Sarisky, M.; Pereira, M.; Repinec, S.; Hochstrasser, R. M. J. Lumin. 1991, 48/49, 204.

(8) Takeuchi, S.; Tahara, T. Chem. Phys. Lett. 1997, 277, 340.

(9) Chachisvilis, M.; Fiebig, T.; Douhal, A.; Zewail, A. H.J. Phys. Chem. A. 1998, 102, 669.

(10) Takeuchi, S.; Tahara, T. J. Phys. Chem. A. 1998, 102, 7740.
(11) Fiebig, T.; Chachisvilis, M.; Manger, M.; Zewail, A. H.; Douhal, A.; Garcia-Ochoa, I.; de La Hoz Ayuso, A. J. Phys. Chem. A. 1999, 103, 7419 .

(12) Bulska, H.; Chodkowska, A. J. Am. Chem. Soc. 1980, 102, 3259

(13) Bulska, H.; Grabowska, A.; Pakula, B.; Sepiol, J.; Waluk, J.; Wild,

U. P. J. Lumin. 1984, 29, 65.

(14) Catalán, J.; Kasha, M. J. Phys. Chem. A 2000, 104, 10812

(15) Steiner, T. Angew. Chem., Int. Ed. 2002, 41, 48. 644.

(17) Sekikawa, T.; Kobayashi, T.; Inabe, T. J. Phys. Chem. B 1997, 101,10645 .

(18) Dufour, P.; Dartiguenave, Y.; Dartiguenave, M.; Dufour, N. Lebuis, A. M.; Belanger-Gariepy, F.; Beauchamp, A. L. Can. J. Chem. 1990, 68 193.

(19) Chou, P. T.; Liao, J. H.; Wei, C. Y.; Yang, C. Y.; Yu, W. S.; Chou, Y. H. J. Am. Chem. Soc. 2000, 122, 986.

(20) After prolong photolysis of 3IAI the crystal turned yellow, accompanied by a decrease of the proton-transfer tautomer emission. Under the same experimental conditions similar photolysis reaction did not occur in 3MAI. It is thus believed that iodine substituents play a role for the observed photochemistry in 3IAI.

(21) Robison, M. M.; Robison, B. L. J. Am. Chem. Soc. 1956, 78, 1247.

(22) Chou, P. T.; Chen, Y. C.; Yu, W. S.; Chou, Y. H.; Wei, C. Y.; Cheng, Y. M. J. Phys. Chem. A 2001, 105, 1731.

(23) Demas, J. N.; Crosby, G. A. J. Phys. Chem. 1971, 75, 991-1024.

(24) Vinogradov, S. N.; Linnell, R. H. Hydrogen Bonding; Van Nostrand-Reinhold: New York, 1971; Chapter 7.

(25) Kim, S. K.; Breen, J. J.; Willberg, D. M.; Peng, L. W.; Heikal, A.; Syage, J. A.; Zewail, A. H. J. Phys. Chem. 1995, 99, 7421.

(26) Fernandez-Ramos, A.; Smedarchina, Z.; Siebrand, W.; Zgierski, M. Z.; Rios, M. A. J. Am. Chem. Soc. 1999, 121, 6280.

(27) Bicerano, J.; Schaefer, H. F., III; Miller, W. H. J. Am. Chem. Soc. 1983, 105,2550 .

(28) Siebrand, W.; Wildman, T. A.; Zgierski, M. Z. J. Am. Chem. Soc. 1984, 106, 4083, 4089 .

(29) Smedarchina, Z.; Siebrand, W. Chem. Phys. 1993, 170, 347.

(30) Benderskii, V. A.; Goldanskii, V. I.; Makarov, D. E. Phys. Rep. 1993, 233, 195.

(31) Benderskii, V. A.; Makarov, D. E.; Wight, C. A. Chemical Dynamics at Low Temperatures; J. Wiley \& Sons: New York, 1994; p 385.

(32) Liu, Y.-P.; Lu, D.-h.; Gonzalez-Lafont, D. G.; Truhlar, D. G.; Garrett, B. C. J. Am. Chem. Soc. 1993, 115, 7806

(33) Bruno, W. J.; Bialek, W. Biophys. J. 1992, 63, 689.

(34) Antoniou, D.; Schwartz, S. D. Proc. Nat. Acad. Sci. U.S.A. 1997 94,12360

(35) Borgis, D.; Hynes, J. T. J. Chem. Phys. 1991, 94, 3619. 